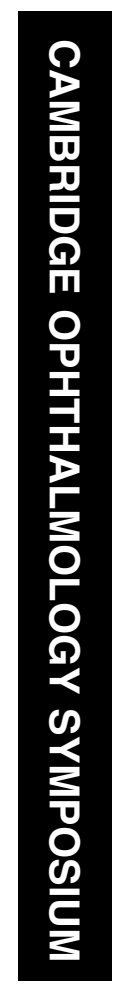

${ }^{1}$ Addenbrooke's University Hospital Cambridge, Cambridge, UK

${ }^{2}$ Moorfields Eye Hospital, London, UK

${ }^{3}$ Department of Ophthalmology, Leiden University Medical Centre, Leiden, The Netherlands

Correspondence:

PG Watson,

Addenbrooke's University

Hospital Cambridge,

11 Perry Court,

Clerk Maxwell Road,

Cambridge CB3 ORS, UK

Tel: + 01223353789 .

E-mail: peter.g.watson@

btinternet.com

${ }^{4}$ This author was formerly Boerhaave Professor at the University of Leiden The Netherlands

Received: 6 October 2008 Accepted: 6 October 2008 Published online: 19

December 2008

Presented at the Cambridge Ophthalmological Symposium September 2008

\section{Prolonged ocular hypotension: would ciliary tissue transplantation help}

\begin{abstract}
Aims Ocular hypotony and phthisis bulbi from persistent fistulae, ciliochoridal detachments, or inflammation, that cannot be treated currently. However, complete shutdown of the ciliary epithelium is rare. Secreting, transplanted ciliary tissue could restore the IOP to a level where further visual damage would not occur or even be reversed.
\end{abstract}

Methods Allografts of ciliary epithelium and its substrate were placed on to the surface of the iris of normal albino rabbits. The progress of the transplanted tissue was followed in the untreated animals, those who had been immunosuppressed and those who had been immunosuppresed together with cold whole body perfusion for up to 55 days. Changes were assessed by slit-lamp observation, luconyl blue staining, fluoresceine angiography, and these were compared with the histology and electron microscopic appearances.

Results Transplants survived the period of ischaemia in the anterior chamber. They started to be revascularised within 4 days and were completely revascularised in $\mathbf{1 2}$ days. Untreated animals showed classical rejection phenomena. However, the ciliary epithelial tissue in those animals who were immunosuppressed and had been subjected to whole body perfusion remained normal and were secreting aqueous, as judged by the histological and electron microscopic appearances.

Conclusions Perfused allografts of ciliary tissue will survive in the normal anterior chamber of the immunosuppressed rabbit, and the electron microscopic evidence indicates that the tissue is producing aqueous. If this can be shown to be adequate in the damaged eye, then ciliary transplantation could be a valuable tool in the management of severe intractable hypotony.
PG Watson ${ }^{1,2,4}$ and L Jovanovik-Pandova ${ }^{3}$

Eye (2009) 23, 1916-1925; doi:10.1038/eye.2008.383; published online 19 December 2008

Keywords: prolonged ocular hypotony; ciliary body; transplantation

Introduction

Prolonged and intractable hypotony is a rare event, but the loss of vision, which accompanies it is devastating both for the patient and the doctor. Treatment is currently rarely effective and other methods need to be developed to restore the intraocular pressure within the normal range.

Aqueous is produced from the free secretory portion of the ciliary body, which faces inwards from the posterior surface of the iris. This consists of fan-like ciliary processes, 70-80 in number, which are largely vascular and covered by two enfolded layers of epithelium. The outer epithelial layer, which is an extension of the pigment epithelium of the retina, is pigmented, and the inner layer, which is the forward prolongation of the sensory retina, is nonpigmented. ${ }^{1}$ In all, $2.5 \mu \mathrm{l}$ of this aqueous humour is produced every minute. It is a protein-free fluid that bathes the lens and structures of the internal eye, providing all their necessary nutrition. The absence of protein in the aqueous is due to the effective bloodaqueous barrier created by tight junctions between the non-pigmented epithelial cells. ${ }^{2}$ The majority of this fluid is drained from the eye through the trabecular meshwork, but some passes out through the uveoscleral pathway and a little through the vitreous. In order that the eye can see clearly, this fluid must be optically clear and must be produced in sufficient quantity to allow the intraocular pressure to be greater than the episcleral venous pressure. To achieve this, the ciliary body must function 
properly and the blood-aqueous barrier must remain intact.

Insufficient aqueous may be produced if large sections of the ciliary body are removed during tumour surgery, if there is fistula formation induced by surgery or trauma, if there is ciliochoroidal detachment, which increases the uveoscleral outflow rate, or there is ciliary body dysfunction due to inflammation or trauma. ${ }^{3}$ All of these conditions can lead to acute ocular hypotony, which is usually reversible. Prolonged or progressive hypotony is on the other hand responsible for irreversible structural and functional changes in the globe, such as lens opacities, corneoscleral shrinkage, and neuronal atrophy. When these changes continue, they can lead to phthisis bulbi, a condition where the globe is permanently shrunken and dysfunctional, and vision is lost. ${ }^{4}$

Although an intraocular pressure of $6 \mathrm{~mm} \mathrm{Hg}$ is defined as ocular hypotension, severe changes in vision do not occur until the pressure falls to $4 \mathrm{~mm} \mathrm{Hg}$ or below. If the pressure can be rapidly elevated to within the normal range, then vision can be restored. If not irreversible changes take place within the eye. In the majority of cases, the hypotension is self-limiting or responds to treatment, but occasionally a vicious cycle of hypotony, blood-aqueous barrier breakdown, inflammation, and oedema, which gives rise to a reduction in aqueous production and even more profound hypotony.

Although various strategies have been described for the surgical management of hypotony from ciliochoroidal detachment, $^{5-8}$ the management of ciliary body dysfunction due to prolonged severe inflammation or malignancy usually proves impossible, because the damaged ciliary body cannot be stimulated medically or surgically. If healthy ciliary body could be transplanted and induced to secrete clear nutritious aqueous, phthisis bulbi could be prevented or reversed, and vision restored.

The purpose of this paper is to examine whether transplantation of functioning ciliary body tissue would be possible, and if so, whether it would be likely to restore visual function to a severely hypotonous eye.

\section{Materials and methods}

\section{Transplantation of ciliary body tissue}

Ciliary tissue and its underlying substrate was transplanted on to the surface of the iris of young adult outbred albino female New Zealand rabbits' eyes using the technique used by C Liu and WY Chan, which had been shown to be effective in preliminary experiments The design of the study, the scoring system, techniques, and methods of evaluation are fully described in Jovanovik-Pandova et $a l^{9}{ }^{9}$ but are summarized here.

\section{Preparation of graft materials}

The ciliary body and the choroid were exposed by dissection through the sclera of the enucleated eye. Here, 2-3 mm segments of ciliary tissue were immediately placed on the iris surface in the anterior chamber of the recipient rabbit or were placed in the culture medium until grafting (Table 1).

\section{Ciliary tissue transplantation procedure}

The anterior chamber was opened through a 2-mm oblique corneoscleral incision superotemporally, using

Table 1 Experimental study designs

\begin{tabular}{|c|c|c|c|c|}
\hline Group & $\begin{array}{c}\text { Number of } \\
\text { animals }\end{array}$ & Donor (one per group) & Graft & Recipients \\
\hline Group A & 9 & Not treated & Not cultured & No immunosuppression applied \\
\hline Group B & 3 & Not treated & Not cultured & $\begin{array}{l}\text { Immunosuppressive treatment with } \\
\text { CsA } 20 \mathrm{mg} / \mathrm{kg} \text { i.m. every second day, } \\
\text { starting } 24 \mathrm{~h} \text { before transplantation }\end{array}$ \\
\hline Group C & 6 & Not treated & $\begin{array}{l}\text { Cultured in F12:MEM medium }(1: 1) \\
\text { for } 3 \mathrm{~h} \text { in an atmosphere of } 7 \% \mathrm{CO}_{2} \text { in } \\
\text { the air at } 37^{\circ} \mathrm{C}\end{array}$ & $\begin{array}{l}\text { Immunosuppressive treatment with } \\
\text { CsA } 20 \mathrm{mg} / \mathrm{kg} \text { i.m. every second day, } \\
\text { starting } 24 \mathrm{~h} \text { before transplantation }\end{array}$ \\
\hline Group D & 6 & Not treated & $\begin{array}{l}\text { Cultured in F12:MEM medium }(1: 1) \\
\text { for } 3 \mathrm{~h} \text { in an atmosphere of } 7 \% \mathrm{CO}_{2} \text { in } \\
\text { the air at } 37^{\circ} \mathrm{C} \text { and supplemented } \\
\text { with VEGF A } 165(60 \mathrm{ng} / \mathrm{ml})\end{array}$ & $\begin{array}{l}\text { Immunosuppressive treatment with } \\
\text { CsA } 20 \mathrm{mg} / \mathrm{kg} \text { i.m. every second day, } \\
\text { starting } 24 \mathrm{~h} \text { before transplantation }\end{array}$ \\
\hline Group E & 6 & $\begin{array}{l}\text { 'Whole body perfusion' of the } \\
\text { donor with UW' solution } \\
\text { before killing and enucleation }\end{array}$ & $\begin{array}{l}\text { Cultured in F12:MEM medium }(1: 1) \\
\text { for } 3 \mathrm{~h} \text { in an atmosphere of } 7 \% \mathrm{CO}_{2} \text { in } \\
\text { the air at } 37^{\circ} \mathrm{C}\end{array}$ & $\begin{array}{l}\text { Immunosuppressive treatment with } \\
\text { CsA } 20 \mathrm{mg} / \mathrm{kg} \text { i.m. every second day, } \\
\text { starting } 24 \mathrm{~h} \text { before transplantation }\end{array}$ \\
\hline Group F & 6 & $\begin{array}{l}\text { 'Whole body perfusion' of the } \\
\text { donor with UW'a solution } \\
\text { before killing and enucleation }\end{array}$ & $\begin{array}{l}\text { Cultured in F12:MEM medium }(1: 1) \\
\text { for } 3 \mathrm{~h} \text { in an atmosphere of } 7 \% \mathrm{CO}_{2} \text { in } \\
\text { the air at } 37^{\circ} \mathrm{C}\end{array}$ & $\begin{array}{l}\text { Immunosuppressive treatment with } \\
\text { CsA } 20 \mathrm{mg} / \mathrm{kg} \text { i.m. every second day, } \\
\text { starting } 24 \mathrm{~h} \text { before transplantation }\end{array}$ \\
\hline
\end{tabular}

${ }^{\mathrm{a} U n i v e r s i t y ~ o f ~ W i s c o n s i n ~ s o l u t i o n . ~}$ 
the $15^{\circ}$ blade and the $3.0 \mathrm{~mm}$ phakoknife. Sodium hyaluronate $3.0 \%$ was used to keep the anterior chamber angle open. The donor ciliary tissue was introduced epithelial side upwards into the anterior chamber and was placed, unsutured, flat on the iris surface close to the pupil margin.

The different experimental designs are shown in Table 1.

Evaluation and scoring of ciliary tissue transplants in the anterior chamber

All animals were observed by slit-lamp examination in a masked manner daily for 20 days (group F for 55 days) after ciliary tissue transplantation. Statistical analysis was carried out by ANOVA test in SPS for Windows (Version 10). A scoring system was devised to describe the colour deviation of the grafts in semiquantitative terms as well as to describe the extent of inflammation and other complications. Photographs of each eye were taken three to four times a week, with a Zeiss anterior chamber camera.

The observations on the external features of the grafts were compared with their histological structures.

Histological examination of dark-red grafts consistently revealed necrotic areas, occluded vessels. and haemorrhages, whereas light-red grafts showed vital epithelial cells and a rich capillary network.

Histopathological evaluation and morphological analysis by transmission electron microscopy of ciliary tissue transplants Histopathological evaluation from serial sections of the grafts in groups C, D, E, and F (Table 1) was performed in a masked manner at the end of the study, respectively on days 20 and 55 .

\section{Anterior segment fluorescein angiography}

The revascularization of the grafts in groups C, D, and E was evaluated by fluorescein angiography. On days 2, 4 , 6,8 , and 12 , photographs were taken with an adapted fluorescein angiographic camera from the start of the injection until the full arteriovenous phase was completed. Late films were made at 10 and $15 \mathrm{~min}$ after injection. The diffusion of dye in the recipient iris and the perfusion of the ciliary body graft were assessed at each time point.

\section{Results}

Clinical evaluation and histological analysis of ciliary allografts in controls

To determine whether ciliary tissue allografts could survive in the anterior chamber of the rabbit eye, we used a control group (Group A, Table 1) where the grafts and the recipient immune response were not influenced before and after transplantation

\section{Clinical evaluation}

Following transplantation, the colour of the grafts was cream-white. Approximately after $24 \mathrm{~h}$, they still preserved their original cream colour and were firmly attached to the iris surface (Figure 1a). The appearance of the transplant before insertion is shown in Figure 1b. The transplants became darkly coloured between 2 and 4 days (Figure 1c) during which period the eye was inflamed with dilatation of limbal capillaries and iris vessels. Between days 5 and 12, all the transplants became progressively redder with visible infiltrating blood vessels. The limbal and iris vessel injection had resolved (Figure 1e). During this period, the transplants shrank to about three-quarters of their original size. As was observed in the preliminary experiments (C Liu, WY Chan and PGW), there was no clinical evidence of rejection. Three months after transplantation, the treated eyes remained free of inflammation and the transplants seemed to be viable. The intraocular grafts did not impair the daily activities of the host animals, including water and food intake.

\section{Histopathological analysis}

Four days after transplantation, the microscopic findings revealed grafts attached firmly to the iris, containing a few ciliary body epithelial cells with moderate pathological changes, surrounded by stromal tissue with congested, possibly occluded blood vessels, haemorrhages, and occasionally necrotic areas (Figure 1d).

Sections made after 8 days of transplantation revealed no change in the amount and histological appearance of epithelial cells present in the graft. However, the amount of haemorrhages and congested vessels decreased, whereas necrotic areas disappeared. At this stage, there was a well-developed vascular anastomosis between the graft and the host iris. Most of the vessels were perfused (normal shape of the erythrocytes, normal endothelial wall, and the presence of luconyl particles in the lumen). These findings confirmed our assumption that the red colour of the graft was associated with revascularization of the grafted tissue.

Sections made on day 12 revealed well vascularized graft tissue, with numerous ciliary processes covered by two layers of epithelial cells (Figure 1f).

Between days 12 and 18, many inflammatory cells, such as lymphocytes and plasma cells, progressively infiltrated the whole transplant. The normal tissue structure was damaged and the few surviving ciliary body epithelial cells showed severe changes (Figures 2a and c). 

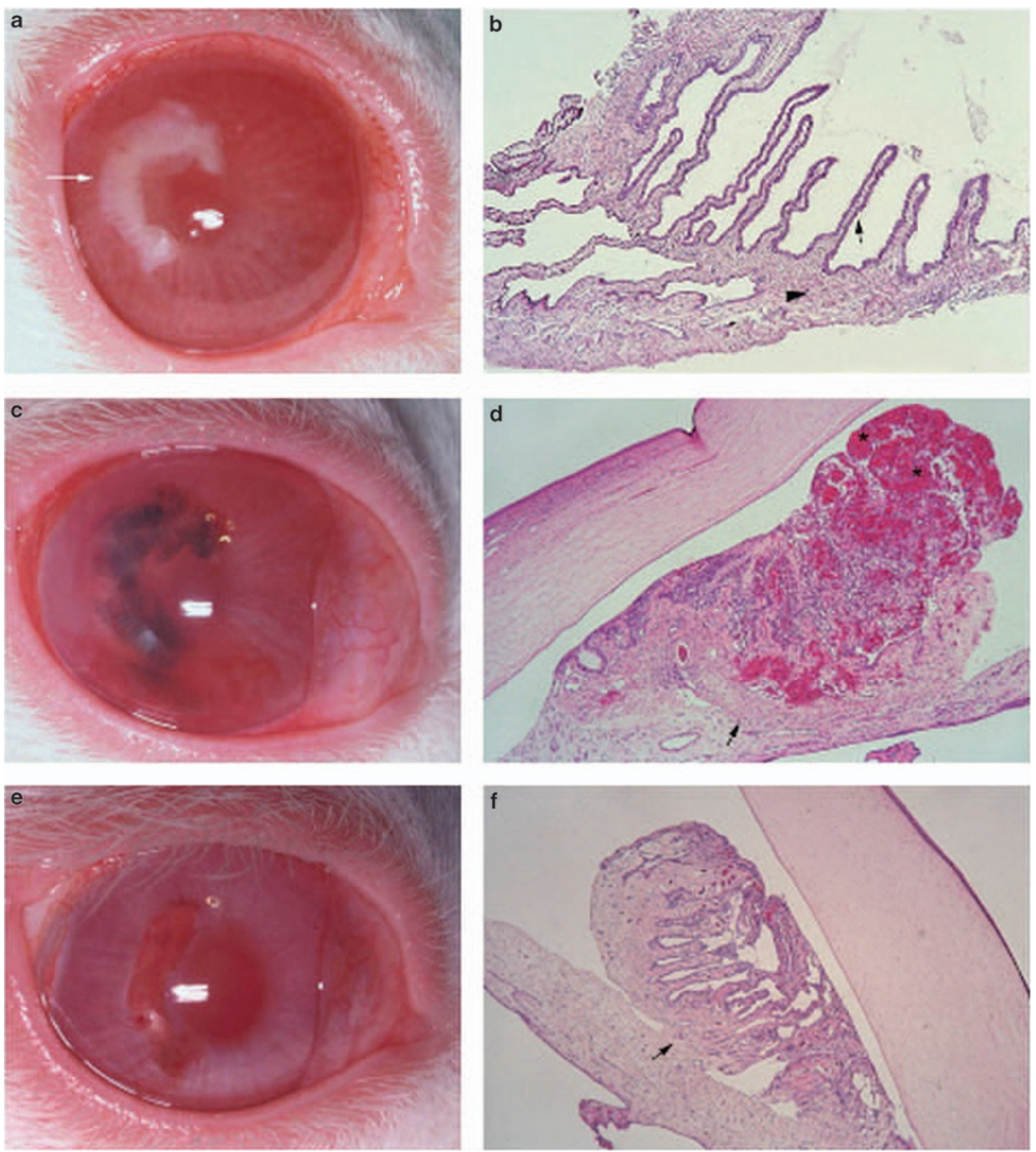

Figure 1 Clinical and histological aspect of the CT transplant in the anterior chamber. (a) After $24 \mathrm{~h}$ of transplantation, the graft preserved its original cream colour (white arrow). (b) Haematoxylin and eosin (HE) staining of the transplant before transplantation displays two layers of ciliary epithelial cells (arrow). (c) Dark red graft in an inflamed eye 4 days after transplantation. Intense vasodilatation of the iris vessels is noted. (d) The transplant is completely attached to the iris surface (arrow). Section reveals necrotic areas, occluded vessels, haemorrhages (asterisk), and a few epithelial cells. (e) After 12 days of surgery, the graft is completely red. (f) Section at 12 days shows that the transplant is attached to the iris surface. There are numerous ciliary processes of normal appearance with two layers of epithelial cells; magnification: $\times 5(b, d$, and $f)$.

Thirty days after transplantation, there was complete infiltration of both the graft and iris with lymphocytes and plasma cells. Epithelial cells were absent. Three months after transplantation, histological analysis revealed a small totally rejected graft consisting only of fibrous tissue with well-developed vessels but without epithelial cells. 

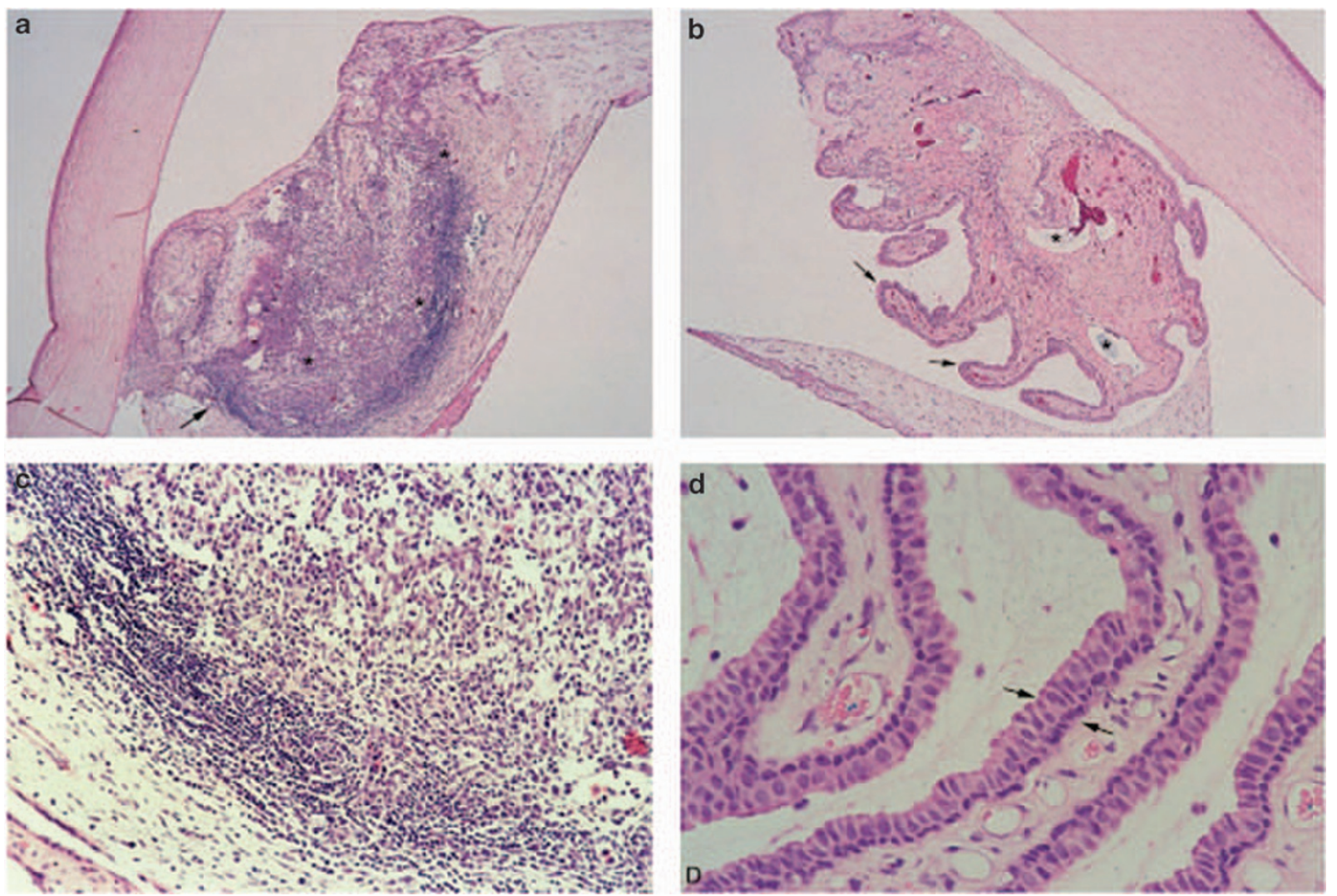

Figure 2 Effect of CsA. Haematoxylin and eosin (HE) sections made 18 days after transplantation. (a andc) Graft tissue in the control rabbit without CsA is completely infiltrated with inflammatory cells, such as lymphocytes and plasma cells (indicated by asterisk). (b and d) Ciliary transplant had vital appearance in rabbit treated with CsA. Ciliary processes have two layers of epithelial cells (indicated by arrows); the stroma has a slight fibrotic reaction; luconyl shows that the vessels are not occluded (luconyl blue particles in the lumen of the vessels indicated by asterisk). Inflammatory cells are not seen; magnification: $\times 5$ (a and b) and $\times 20$ (c and d).

On the basis of the findings above, we conclude that incompatible ciliary tissue allografts transplanted in the anterior chamber of the rabbit eye undergo irreversible immune rejection and do not function, although macroscopic observations did not reflect this.

\section{Clinical evaluation and histological analysis of ciliary allografts in immunosuppressed rabbits}

As the control animals (Group A, Table 1) experienced a classical rejection phenomenon, systemic ciclosporine (CsA, $20 \mathrm{mg} / \mathrm{kg}$ ) was given to three animals (Group B, Table 1) by intramuscular injection, starting $24 \mathrm{~h}$ before surgery and continued every second day until the animal was killed. ${ }^{10}$ Results of group A and group B were compared.

Clinical evaluation revealed no difference in the appearance of the transplants. On the other hand, histopathological findings differed markedly from those in the control group. The sections from the eyes, enucleated 18 days after transplantation, revealed many histologically normal looking ciliary body epithelial cells with minimal pathological (Figures $2 \mathrm{~b}$ and $\mathrm{d}$ ) changes. There were no inflammatory cells present. The delayed revascularization of the transplant tissue seen in the control group was not modified by the immunosuppresion. Occluded vessels and haemorrhages remained numerous during the first 7-8 days.

\section{Clinical evaluation and histological analysis of ciliary allografts in groups $C, D$, and $E$}

As systemic CsA did not improve revascularization, experiments were undertaken to try to reduce the ischaemic period after transplantation by the use of VEGF and 'whole donor body perfusion' (Table 1).

Six grafts were incubated in a culture medium supplemented by VEGF-A $165^{11}$ before transplantation (Group D, Table 1). Six additional rabbits received grafts from a donor animal that underwent whole body perfusion using the University of Wisconsin solution cooled at $4^{\circ} \mathrm{C}$ (Group E, Table 1), immediately before killing and enucleation of the eyes. ${ }^{12-14}$ The third group (Group C, Table 1) of six animals received grafts that 
were only incubated in the culture medium mentioned above, and these were used as a control. Reperfusion of the allografts was also evaluated by anterior segment fluorescein angiography.

\section{Clinical evaluation}

The integrity of the vessels and the degree of neovascularisation was assessed by the use of luconyl blue and fluorescein angiography.

The grafts incubated in medium with VEGF (group D) and the grafts obtained from the perfused donor (group E) were more rapidly revascularized and reperfused than the controls. The dye diffusion occurred in the transplants from the control group for the first time on day 4, but earlier in the VEGF group. Figure 3 compares the clinical aspect of the eyes with luconyl blue and the fluorescein angiograms made on days 4,8 , and 12 . No leakage of fluoresceine occurred into the anterior chamber in any angiograms.

Quantitative assessment of the graft size revealed gradual shrinkage of the mass of the transplants. At day 20 , the size of all grafts (except one) was reduced to $70-80 \%$ of their original measurements. No significant difference was shown between the three groups.

\section{Histopathological analysis}

Animals killed 18 days after the surgery showed that perfusion of the vessels in the ciliary body tissue with UW solution before transplantation increases the epithelial cell survival, whereas VEGF did not improve the survival.

Long-term survival of the transplants from a perfused donor animal was analysed by histological examination 60 days after the transplantation (Table 1, group F). The epithelial cells observed at the graft surface were histologically normal, but the central part of the grafts was characterized by severe interstitial fibrosis (Figure 4).

\section{Ultra structure}

Electron microscopy of ultra thin sections from the ciliary tissue transplant in donor perfusion group $\mathrm{E}$ revealed only very slight architectural alterations from normal. The inner layer of non-pigmented cells was slightly thicker than in the controls, but the characteristic interdigitations (b-cytomembranes) were obviously present (Figure 5). The intercellular contacts (tight junctions) between the two layers were intact.

Intracellular organelles appeared normal in the cells of both epithelial layers, and particularly mitochondria were present in large numbers. The thin layer of a collagen-like substance, which was seen in the normal controls, was thicker over the transplants and contained a few cells.
We certify that all applicable institutional and governmental regulations concerning the ethical use of animals were followed during this research

\section{Discussion}

Loss of vision from irreversible damage to the ciliary body due to trauma, surgery, or inflammation is a major disaster for which there is, currently, no treatment. As a destroyed ciliary body cannot be treated or stimulated to function, progressive ocular hypotony and phthisis bulbi are inevitable consequences. The only possible method of reversing this process would be by replacing the damaged tissue with normal, functioning ciliary body tissue. If the transplant is not rejected, well vascularized, and retains an epithelial structure, which is capable of aqueous secretion, it could partly take over the function of the damaged tissue. Sufficient production of the aqueous humour by the transplant could maintain the intraocular pressure and prevent intraocular structural changes.

The experiments described here show that with immunosuppression and perfusion of the donor tissue in a manner similar to that used for other organ transplants ${ }^{15}$ it is possible to transplant ciliary tissue in the rabbit, which is histologically normal in appearance. There is no reason to suspect that similar transplants would not survive in the human. Perfusion of the enucleated human eye is possible through the relatively large choroidal and retinal vessels around the optic nerve.

For an organ transplant to be successful, it must take on the function of the damaged host tissue and must continue to function for as long as necessary in the host. As yet, it is not known whether these transplants produce sufficient aqueous to replace or supplement that produced by an underactive or damaged ciliary body. It is likely that aqueous is being secreted because we compared the cytoskeletal architecture of the normal ciliary body epithelial cells with the transplants by transmission electron microscopic examination and they appear absolutely normal with secreted granules being extruded. However, aqueous production is in part dependant on a high pressure within the terminal capillaries of the ciliary vascular plexus. Whether this same pressure differential exists in the anastomotic vessels has not been determined. There is a significant period of relative ischaemia, whereas the vessels in the transplant anastamose with the host. Although it has been suggested that pancreatic tissue fragments transplanted into the anterior chamber of a rat eye were revascularized within $24 \mathrm{~h},{ }^{16}$ in our study, fluorescein dye in the ciliary tissue transplants was visible for the first time on day 4. Dye diffusion into the whole transplant 

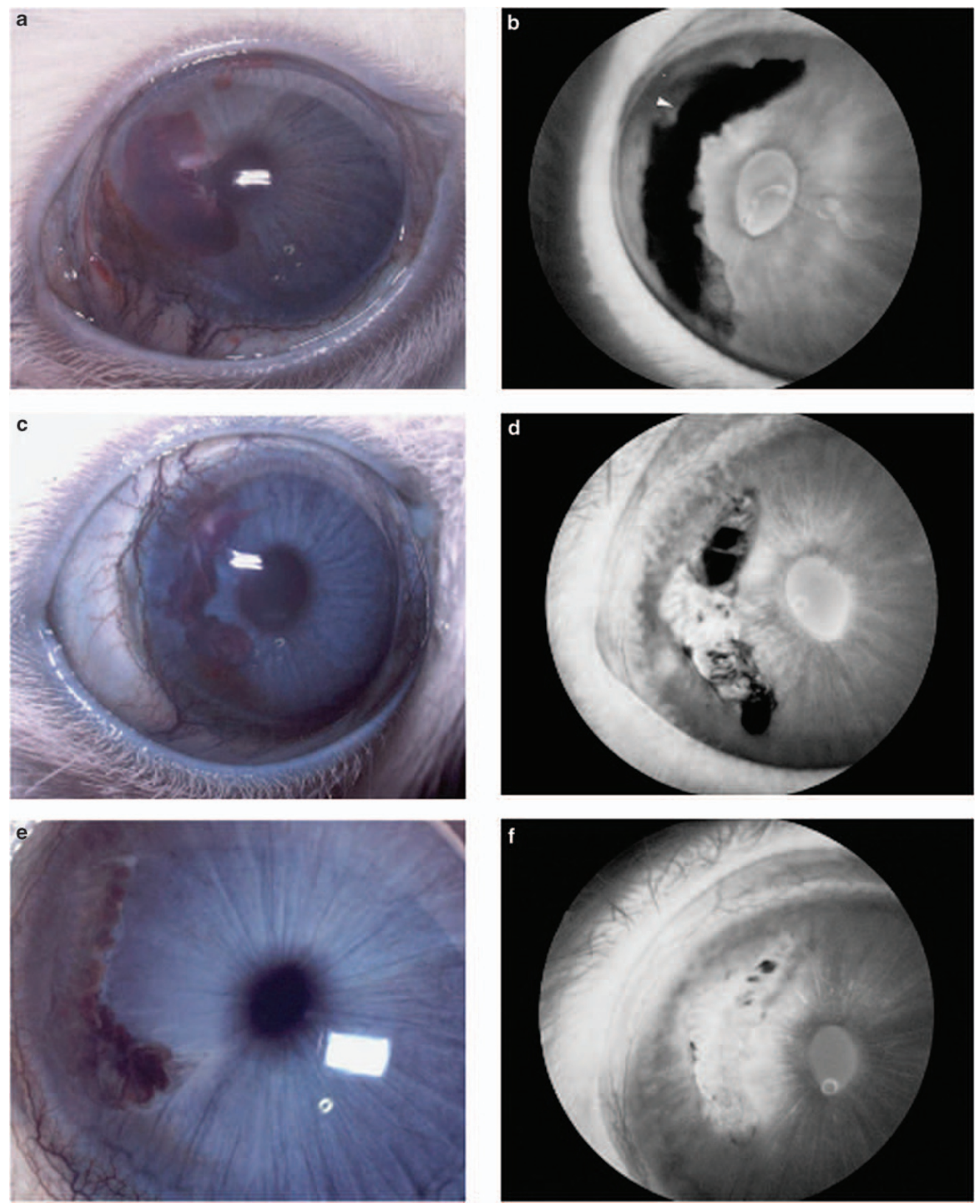

Figure 3 Luconyl blue injection and fluorescein angiograms at the same time point. (a, control) After 4 days of transplantation, the greater part of the transplant is still red except for the small blue areas where luconyl blue diffused in the transplant vessels (arrow). (b, control) At the same time, the fluorescein angiogram shows only a small area where graft vessels are perfused (arrow). (c, VEGF) After 8 days of transplantation, approximately half of the tissue is blue because of irrigated vessels, confirmed by the dye diffusion in the angiogram made on the same day (d, control). (e, VEGF group and f, control) After 12 days of transplantation, the complete graft is irrigated by luconyl blue and fluoresceine. The fluorescein angiogram also shows the localized dilatation of the iris vessels under the transplant. There is no evidence of fluoresceine in the anterior chamber. 

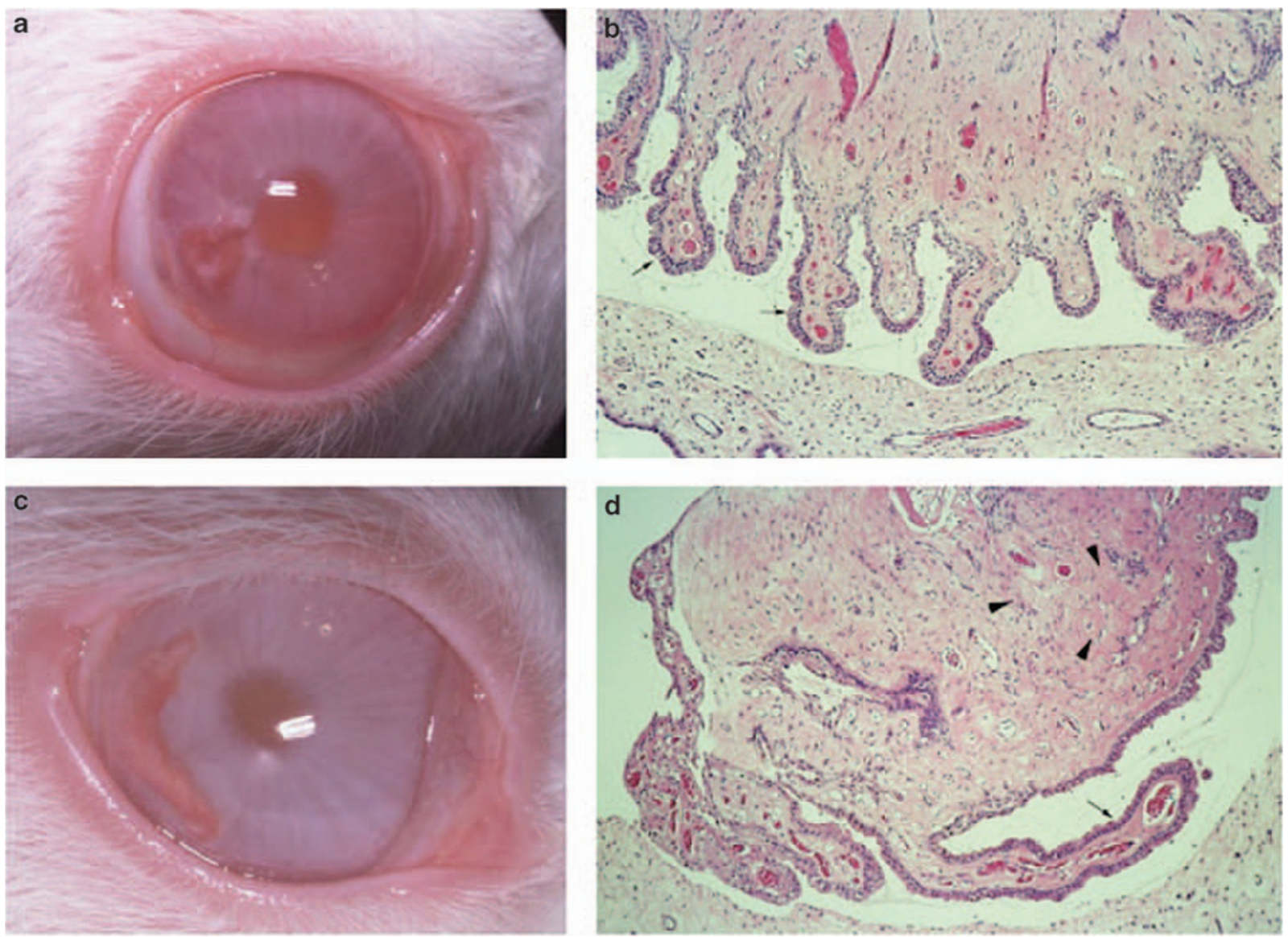

Figure 4 Clinical and histological aspects of CT transplants, 18 and 55 days after transplantation. This figure shows that despite of similar clinical appearance of both transplants, at day 18 (a) and day 55 (c), there is considerable difference in the tissue structure. (b) An HE section from eye (a) reveals an apparently normal viable transplant and numerous ciliary processes covered by two layers of epithelial cells. The stroma has a small amount of fibrous tissue and normal looking vessels. (d) HE section from eye (b) reveals that the epithelial layer is only present at the graft surface and there is a strong developed stromal fibrotic reaction.

was not complete before day 12 (Figure 3). These observations imply that the graft capillary network was linked to the host circulation not earlier than 4 days after transplantation. Fortunately, however, there was no indication that the blood-aqueous barrier in the graft tissue was damaged, as there was no fluorescein leakage from the graft vessels, or from the transplant into the anterior chamber.

The anterior chamber is able to supply the necessary nutrients and is recognized as a classic example of a privileged site, which has previously been used for investigation of various solid tissue transplants (corneal allografts, pancreatic tissue, brain tissue, skin, thyroid. and so on). Results from some of these studies indicate that the prolonged survival of the histologically incompatible allografts is partly due to the immunosuppressive microenvironment in the anterior chamber. ${ }^{17}$ The experimental rabbit anterior chamber contains fluid from a normally functioning ciliary body. This, no doubt, provided an environment in which the epithelial tissue could survive the ischaemia, but this might not be the case if the eye was already severely inflamed or otherwise compromised. VEGF induced an earlier and more completely developed vascular network in the transplants as shown by the angiograms and histology, but it also induced an extensive fibrotic reaction in the grafts. As a consequence, only a few ciliary epithelial cells survived.

All the transplants shrank in size following the operation, but in spite of this, the histological appearance remained normal and they were not initially affected by fibrosis. However, interstitial fibrosis was found in all the long-term grafts, and so it is uncertain how long the transplants would continue to function. ${ }^{18}$

As there was no leakage of fluoresceine into the anterior chamber during angiography, it is probable that the tight junctions have remained intact.

In spite of these caveats, it is probable that a significant amount of aqueous is produced by these transplants. If this can be shown to be the case, then what are the 

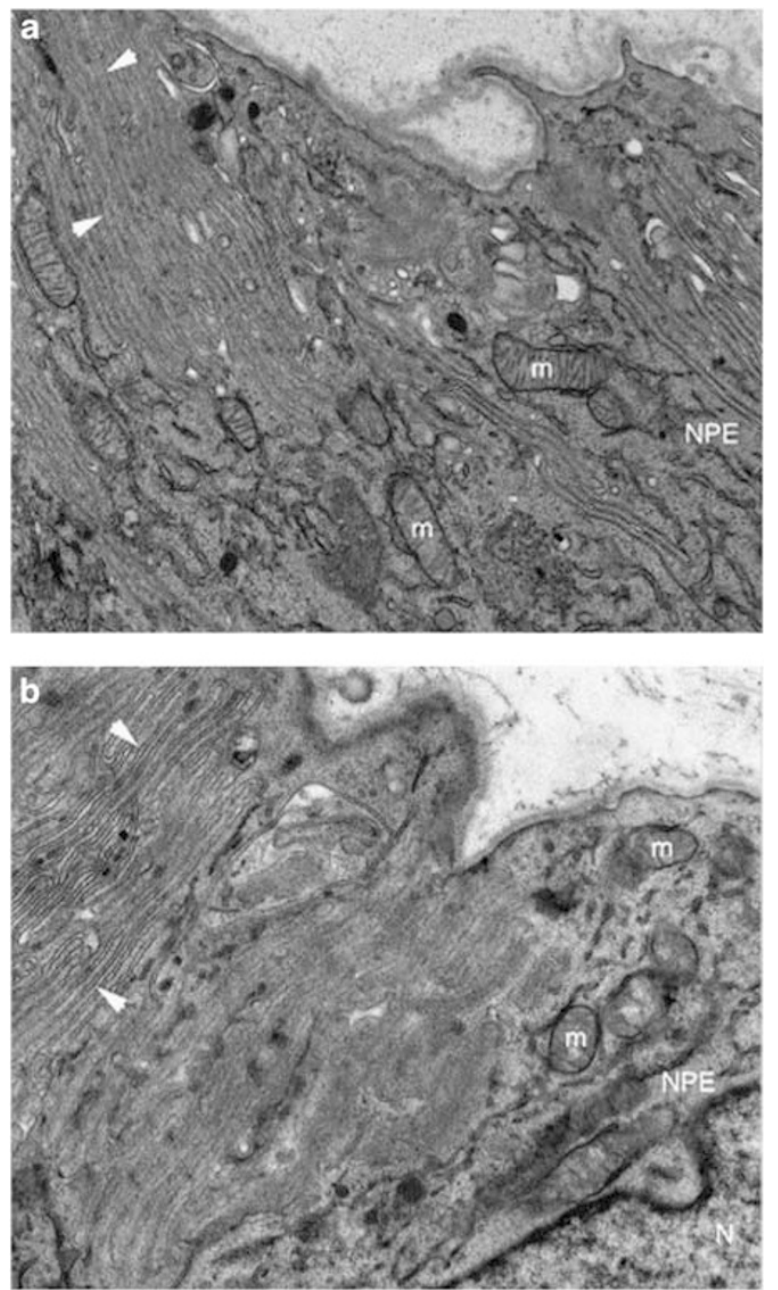

Figure 5 Electron microscopy of non-pigmented epithelium cell in (a) control ciliary tissue and (b) ciliary tissue transplant. $\mathrm{NPE}=$ non-pigmented epithelium; $\mathrm{N}=$ nucleus; $\mathrm{m}=$ mitochondria; arrow heads=basolateral interdigitations ( $\beta$-cytomembranes). The appearance of the control and the transplant epithelial cells at day 18 is almost identical. The tight junctions between the cells are intact; the organelles are normal and the enzyme-producing cytomembranes (arrowheads) appear identical.

indications for using them? The commonest causes of persistent hypotony are excessive leakage of aqueous from a fistula created surgically or by trauma or a ciliochoroidal detachment. Various strategies for sealing the leak and for treating the increased uveoscleral flow induced by ciliochoroidal detachment, have been devised and can be successful they need to be performed before permanent alteration of function has occurred. This is a difficult decision to take, but delay is disastrous. The same applies to damage to the ciiliary body from chronic uveitis in which there is a breakdown in the blood-aqueous barrier, leakage of ciliary vessels and a reduction of aqueous production. Fortunately, the reserve in the ciliary body is enormous and the aqueous production needs to be reduced to $10 \%$ of the normal $2.5 \mu \mathrm{l} / \mathrm{min}$ in an otherwise normal eye before the eye becomes hypotonous. ${ }^{19}$ Even in the most severe cases. it is very unusual for the secretion to be totally shut down. If any aqueous is being produced, then a supplement provided by a ciliary tissue transplant would break the vicious cycle. This is particularly true where hypotony is the result of large segments of the ciliary body being removed in tumour surgery or trauma. Therefore, it might not be vital that a transplant survives for a prolonged period because once the aqueous production has been boosted to the level where the IOP is within the normal limits, the ciliary body will recover, the oedema disappear, and function will be at least partially restored.

\section{Acknowledgements}

We thank Christopher Liu and Professor Chan of the Department of Anatomy Chinese, University of Hong Kong, for performing the initial experiments, Dr Martine Jager of the Department of Ophthalmology, University of Leiden, for the facilities to carry out this work and FA Prince from Department of Pathology, Leiden University Medical Centre, for his technical assistance. We also thank Experimental Eye Research for permission to use the previously published illustrations.

\section{References}

1 Duke-Elder S, Wybar KC. The anatomy of the visual system. In: Duke-Elder S (ed). System of Ophthalmology, 2nd edn. Henry Kimpton: London, 1961, pp 146-148.

2 Raviola G. The structural basis of the blood-ocular barriers. Exp Eye Res 1997; 25(Suppl): 27-63.

3 Hermann DS. Postsurgical hypotony: relationship to fistulization, inflammation, chorioretinal lesions, and the vitreous. Surv Ophthalmol 1996; 41: 97-124.

4 Coleman DJ. Evaluation of ciliary body detachment in hypotony. Retina 1995; 15: 312-318.

5 Demeler U. Surgical management of ocular hypotony. Eye 1998; 2: 77-79.

6 Helbig H, Foerster MH. Management of hypotonous cyclodialysis with pars plana vitrectomy, gas tamponade, and cryotherapy. Ophthalmic Surg Lasers 1996; 27: 188-191.

7 O'Connell SR, Majji AB, Humayun MS, de Juan Jr E. The surgical management of hypotony. Ophthalmology 2000; 107: 318-323.

8 Costa VP, Arieri ES. Hypotony maculopathy. Acta Ophthalmol Scand 2007; 85: 586-597.

9 Jovanovik-Pandova L, Watson PG, Lu C, Chan WY, de Wolff-Rouendaal D, Barthen ER et al. Ciliary tissue transplantation in the rabbit. Exp Eye Res 2006; 82(2): 247-257.

10 Faulds D, Goa KL, Benfield P. Cyclosporin. A review of its pharmacodynamic and pharmacokinetic properties, and therapeutic use in immunoregulatory disorders. Drugs 1993; 46: 953-1040. 
11 Rosenstein JM, Mani N, Silverman WF, Krum JM. Patterns of brain angiogenesis after vascular endothelial growth factor administration in vitro and in vivo. Neurobiology 1998; 12: 7086-7091.

12 Collins GM. What solutions are best? Overview of flush solutions. Transplantation Proc 1997; 29: 3543-3544.

13 Mühlbacher F, Langer F, Mittermayer C. Preservation solution for transplantation. Transplantation Proc 1999; 31: 2069-2070.

14 Hauet T, Goujon JM, Vandewalle A. To what extent can limiting cold ischaemia/reperfusion injury prevent delayed graft function? Nephrol Dial Transplant 2001; 16: 1982-1985.
15 Belzer FO, Southard JH. Principles of solid organ preservation by cold storage. Transplantation 1988; 45: 673-676.

16 Adeghate E. Host-graft circulation and vascular morphology in pancreatic tissue transplants in rats. Anat Rec 1998; 251: 448-459.

17 Niederkorn JY. Immune privilege and immune regulation in the eye. Adv Immunol 1989; 48: 191-226.

18 Waller JE, Nicholson MR. Molecular mechanisms of renal allograft fibrosis. B J Surgery 2001; 88: 1429-1441.

19 Pederson JE. Ocular hypotony. Trans Ophthalmol Soc UK 1986; 105(Part 2): 220-226. 